\title{
High-frequency jet ventilation: a case report
}

\author{
KALPALATHA K GUNTUPALLI, ARNOLD SLADEN, MIROSLAV KLAIN
}

From the University of Pittsburgh School of Medicine, Montefiore Hospital, Pittsburgh, Pennsylvania

Treatment of bilateral pneumonia with pneumatoceles poses a difficult problem of management in patients requiring mechanical ventilation. The presence of a bronchopleural fistula compounds the problem. The peak inspiratory airway pressures with conventional ventilators potentially can generate an air leak, or increase the leak through an existing fistula. High-frequency jet ventilation is capable of appreciably decreasing the airway pressures during mechanical ventilation ${ }^{1}$ and has been used in the treatment of a large airway leak. ${ }^{2}$ We report the use of this method in the management of a patient with acute respiratory failure from pneumonia, pneumatoceles, and bronchopleural fistula.

\section{Case report}

A 23-year-old man was admitted after a 20-metre fall. No evidence of fracture of long bones or ribs or of pulmonary contusion was noted. The chest radiograph and arterial blood gases were within normal limits. Computed tomography showed cerebral oedema. Intracranial pressure was monitored and cerebral oedema treated with controlled hyperventilation, mannitol, and corticosteroids. Five days after admission the patient developed fever; bilateral pulmonary infiltrates were observed on the chest film. Enterococci and Haemophilus infuenzae, both sensitive to cefamandole, were cultured from the sputum, and he was treated with appropriate doses of the antibiotic, but without improvement. Since his recovery was expected to be slow a tracheostomy was performed.

Ten days after admission pneumatoceles in the left lower lung zone and a left pleural effusion were observed on the chest film. Shortly afterwards he developed tachypnoea (respiratory rate $>45 / \mathrm{min}$ ) and sweating, associated with a $10 \%$ pneumothorax. Mechanical ventilation provided a tidal volume of $750 \mathrm{ml}, 10 / \mathrm{min}$; positive end-expiratory pressure was $2.5 \mathrm{~cm} \mathrm{H}_{2} \mathrm{O}$ and fractional inspired oxygen $\left(\mathrm{F}_{\mathrm{I}} \mathrm{O}_{2}\right) \mathbf{0 . 4}$; arterial oxygen tension $\left(\mathrm{PaO}_{2}\right)$ was $10 \cdot 13 \mathrm{kPa}$ $(76 \mathrm{~mm} \mathrm{Hg})$, arterial carbon dioxide tension $\left(\mathrm{PaCO}_{2}\right) \mathbf{3 . 8 7}$ $\mathrm{kPa}(29 \mathrm{~mm} \mathrm{Hg}$ ), and $\mathrm{pH} \mathrm{7.50}$. Thoracentesis was performed and a chest tube inserted, and a small air leak was noted. About $500 \mathrm{ml}$ of blood-stained fluid (pH of 7.16, white cell count of $8.7 \times 10 \% / 1(97 \%$ polymorphs), glucose $1.5 \mathrm{mmol} / 1(27 \mathrm{mg} / 100 \mathrm{ml}))$ was drained. Group D streptococcus was cultured from pleural fluid and anaerobic cultures gave negative results. Tracheal aspirate at this time grew Proteus sp, group D streptococci and enterococci, which were sensitive to tobramycin and ampicillin, with which he was treated. At this time the patient was able to open his eyes on command. During the next 24 hours

Address for reprint requests: Dr KK Guntupalli, Pittsburgh School of Medicine, Montefiore Hospital, Pittsburgh, Pennsylvania, USA. tachypnoea persisted, with progression of bilateral pulmonary infiltrates. When the $\mathrm{F}_{\mathrm{I}} \mathrm{O}_{2}$ was 0.4 and the positive end-expiratory pressure $7.5 \mathrm{~cm} \mathrm{H}_{2} \mathrm{O}, \mathrm{PaO}_{2}$ was $7.87 \mathrm{kPa}$ (59 mm Hg), $\mathrm{PaCO}_{2} 4 \cdot 27 \mathrm{kPa}(32 \mathrm{~mm} \mathrm{Hg}$ ), and $\mathrm{pH} 7 \cdot 48$. In view of the continued respiratory distress, rapidly progressive pneumonia, pneumatoceles, and bronchopleural fistula, high-frequency jet ventilation was initiated at a rate of $100 / \mathrm{min}$, driving pressure $25 \mathrm{lb} / \mathrm{in}^{2}(172 \mathrm{kPa})$, inspiratory time $30 \%$, and positive end-expiratory pressure $5 \mathrm{~cm}$ $\mathrm{H}_{2} \mathrm{O}$. The patient appeared comfortable and spontaneous respiratory rates remained less than 25 per minute. When $\mathrm{F}_{\mathrm{I}} \mathrm{O}_{2}$ was $0.74 \mathrm{PaO}_{2}$ was $27.47 \mathrm{kPa}(206 \mathrm{~mm} \mathrm{Hg}), \mathrm{PaCO}_{2}$ $4 \cdot 13 \mathrm{kPa}(31 \mathrm{~mm} \mathrm{Hg})$, and $\mathrm{pH} 7 \cdot 50$. Gradually the positive end-expiratory pressure was discontinued, and $\mathrm{F}_{\mathrm{I}} \mathrm{O}_{2}$ decreased to $0.3 ; \mathrm{PaO}_{2}$ was then $15.73 \mathrm{kPa}(118 \mathrm{~mm} \mathrm{Hg})$, $\mathrm{PaCO}_{2} 3.73 \mathrm{kPa}(28 \mathrm{~mm} \mathrm{Hg}$ ), and $\mathrm{pH} \mathrm{7.54}$. The air leak was minimal on high-frequency jet ventilation without positive end-expiratory pressure. During the succeeding six days the pneumatoceles and infiltrates resolved. Highfrequency jet ventilation was discontinued and the patient was successfully decannulated. The chest tube was replaced with a Foley catheter for the drainage of empyema. The patient was responsive and able to sit in a chair.

\section{Discussion}

This patient presented a difficult problem in management because of the bilateral pneumonia, with progression to pneumatocele formation and the need to provide ventilatory support in the presence of pneumothorax and bronchopleural fistula. Mechanical ventilators, with or without positive end-expiratory pressure, can potentially cause barotrauma and generate a fistula or increase air leaks through an existing one. Several factors, such as peak respiratory airway pressure, application of positive endexpiratory pressure, and the presence of underlying lung disease, have been implicated in the causation of barotrauma. With conventional ventilators the peak inspiratory pressure changes in relation to pulmonary compliance. Varying alveolar ventilation can occur at high peak pressures, owing to greater compression volume or to the fact that the volume is vented when the pressure limit is reached. High-frequency jet ventilation is a time-cycled ventilator and uses a high-pressure source of gas to deliver jets of oxygen or air-oxygen mixtures and also entrains air or an air-oxygen mixture by Venturi principle. It has a negligible internal volume and thus an insignificant compression volume. This mode of ventilation provides adequate alveolar ventilation at lower pressures and is independent of lung compliance. The bronchopleural fistula can give rise to large inspiratory leaks resulting in decreased alveolar ventilation or expiratory leak causing an inability 
to maintain positive end-expiratory pressure and hence hypoxaemia. In our patient the air leak was not large and the aim was not to increase it. The need to provide ventilatory assistance for the management of acute respiratory failure in the presence of pneumatoceles and bronchopleural fistula contraindicated high peak airway pressures. High-frequency jet ventilation was the mode of choice in these circumstances. ${ }^{3}$

In patients breathing out of phase with the ventilators a further increase in airway pressures occurs. Narcotics or muscle relaxants may be required to control this asynchrony. High-frequency jet ventilation, by contrast, is well tolerated by the patients, can be superimposed on spontaneous breathing, and does not require the use of narcotics or muscle relaxants. ${ }^{4}$

In addition, high-frequency jet ventilation prevents aspiration. ${ }^{5}$ In neurologically compromised patients and those with loss of protective airway reflexes there is a danger of aspiration despite adequate seal with tracheostomy cuffs. High-frequency jet ventilation is indicated in these patients quite apart from its use in acute respiratory failure.

\section{References}

' Klain M, Smith RB. High frequency percutaneous transtracheal jet ventilation. Crit Care Med 1977;5:280-7.

${ }^{2}$ Carlon GC, Ray C, Klain M, McCormack PM. High frequency positive pressure ventilation in management of a patient with bronchopleural fistula. Anesthesiology 1980;52:160-2.

${ }^{3}$ Carlon GC, Kahn RC, Howland WS, Ray C, Turnbull AD. Clinical experience with high frequency jet ventilation. Crit Care Med 1981;9:1-6.

4 Klain M, Kalla R, Sladen A, Guntupalli K. Weaning from respiratory support by high frequency jet ventilation. Crit Care Med 1981;9:191.

${ }^{5}$ Klain M, Keszler H. High frequency ventilation prevents aspiration. Crit Care Med 1980;8:242. 